\title{
HISTÓRIA E ORGANIZAÇÃO DO SISTEMA EDUCATIVO FRANCÊS: DA ESCOLA MATERNAL À UNIVERSIDADE
}

\author{
Fábio Mariano Da Paz, André D. Robert \\ Faculdade de Ciências e Tecnologia de Birigui -FATEB, Birigui/SP. E-mail: fmpaz@ig.com.br.
}

\begin{abstract}
RESUMO
Este artigo tem como objetivo apresentar parte da pesquisa "Gestão Escolar, Formação Docente e Qualidade da Educação Pública em Lyon - França e em Birigui - Brasil", realizado por ocasião de um pós-doutorado junto ao Laboratório de Educação, Cultura e Políticas do Institut des Sciences et Pratiques d'Éducation et de Formation (ISPEF), pertencente à Universidade de Lyon 2, no período de abril de 2016 a fevereiro de 2017. Representa o esforço de efetuar uma análise do sistema educativo francês e, neste contexto, de discutir brevemente seu percurso histórico, seus princípios, sua estrutura hierárquica e seus níveis de ensino, desde a escola maternal até a universidade. Os dados mostram que mesmo um país desenvolvido com a França possui seus percalços e dificuldades na implementação de suas políticas educacionais.
\end{abstract}

Palavras-chave: sistema educativo, organização educacional; política educacional.

\section{HISTORY AND ORGANIZATION OF THE FRENCH EDUCATIONAL SYSTEM: From Nursery School To University}

\begin{abstract}
This article aims to present part of the research "School Management, Teaching Training and Quality of Public Education in Lyon - France and Birigui - Brazil", held on the occasion of a postdoctoral fellowship with the Laboratory of Education, Culture and Policies of the Institut des Sciences et Pratiques d'Éducation et de Formation (ISPEF), belonging to the University of Lyon 2, from April 2016 to February 2017. It represents the effort to carry out an analysis of the French educational system and, in this context, to discuss briefly its historical course, its principles, its hierarchical structure and its levels of education from the nursery school to the university. The data shows that even a developed country like France has its mishaps and difficulties in implementing its educational policies.
\end{abstract}

Keywords: educational system; educational organization; educational politics. 


\section{INTRODUÇÃO}

Este artigo é oriundo da pesquisa de pós-doutorado em educação intitulada "Gestão Escolar, Formação Docente e Qualidade da Educação Pública em Lyon - França e em Birigui Brasil", realizada junto ao Laboratório de Educação, Cultura e Políticas do Institut des Sciences et Pratique d'Éducation et de Formation (ISPEF), pertencente à Universidade de Lyon 2, no período de abril de 2016 a fevereiro de 2017.

Pretende-se, por meio dele, apresentar brevemente os principais aspectos históricos e político-educacionais que subsidiaram a organização e estruturação do sistema educativo francês, tal como se encontra atualmente.

A fim de dar cabo às suas intenções, este artigo está organizado em duas partes. Na primeira, focaliza-se, de modo bastante sucinto, o histórico de consolidação da educação pública, a partir das principais legislações e reformas empreendidas desde a 3a República. Na segunda, busca-se destacar as características mais marcantes de sua estrutura administrativa e de seus níveis de ensino, perpassando, ainda que de forma rápida, a lógica adotada pela política de formação inicial de docentes nas universidades públicas.

No que concerne à forma redacional adotada, tendo-se em conta a especificidade do sistema educativo francês e sua complexidade, pretende-se manter algumas designações e termos em língua francesa, acrescentando-se a eles outros em português que sejam equivalentes ou próximos para efeitos de compreensão.

\section{A EDUCAÇÃO NA FRANÇA A PARTIR DA 3a REPÚBLICA}

De acordo com Deubel et al (2011) até a Revolução Francesa o ensino escolar das crianças e jovens na França permanece sob à responsabilidade da esfera privada. Embora as instituições comecem a responder pelo ensino (o comércio pelo ensino profissional, a igreja pela formação das elites - os jesuítas em particular), o Estado se mantém fora do campo de formação.

Em 1833 com a Lei Guizot, o Estado dá um passo importante na mudança desse cenário, ao determinar que cada comuna mantenha uma escola primária para ensinar as bases do saber a todos os franceses. Apesar disto, o compromisso do Estado com a educação é insuficiente, em particular, devido à inexistência de obrigatoriedade escolar e financiamento.

A escola somente se torna obrigatória para todos entre 1881 e $1882 \mathrm{com}$ as leis de Jules Ferry, que estabelece a responsabilidade estatal de formar todos os franceses entre 6 e 12 anos de idade. Esta formação passa a ser sancionada com a expedição de um diploma: o certificado de estudos primários.

Auduc (2005) considera que a Lei Ferry foi a primeira revolução escolar da França, ao impulsionar toda a escolarização do século XIX. Seu objetivo repousava sobre a implementação de uma forte ideologia republicana e cívica na formação dos professores e alunos.

Em seu artigo 4음 a Lei Jules Ferry deixa a escolha do local de instrução às famílias, pois tal como ainda é hoje, a escola não é obrigatória, apenas a instrução. Essa lei rompeu com o monopólio da igreja quanto à educação dos jovens franceses e definiu o princípio da laicidade, substituindo a educação religiosa pela cívica.

A segunda revolução escolar, a reforma do Ministro René Haby, ocorre em função das necessidades econômicas, incluindo na faixa de escolarização os jovens de 12 a 16 anos e assegurando a todos a gratuidade dos estudos nos colégios. Esta reforma impulsiona ainda mais o caráter obrigatório da instrução dos jovens, que foi estabelecida até os 16 anos em 1959.

A terceira revolução escolar da França acontece a partir de 1984 para responder à aceleração das mudanças técnicas, exigindo a ampliação da escolarização dos alunos ao nível do baccalauréat - $\mathrm{BAC}^{1}$. A fórmula « $80 \%$ da faixa etária no baccalauréat » é a palavra de ordem.

\footnotetext{
${ }^{1} \mathrm{O}$ baccalauréat é o primeiro diploma universitário francês que sanciona o fim dos estudos secundários e dá o direito de acesso ao ensino superior. 
Em 1989, partindo do Bicentenário da Revolução Francesa, a Lei de Orientação, chamada Lei Jospin é adotada. Ela contém 36 artigos e um relatório anexo que estabelece os objetivos principais desde a école maternelle (pré-escola) à universidade. Seu primeiro artigo declara a educação como uma prioridade nacional e que o serviço público deverá estar à disposição dos alunos e estudantes, reafirmando-se, também, o princípio da igualdade de oportunidades.

De acordo Auduc (2005), as inovações introduzidas pela lei de 1989 são: a organização da escolaridade em ciclos; mudança de procedimentos de orientação vocacional; criação de conselhos de delegados-alunos; criação de institutos universitários de formação de professores, obrigação de cada instituição desenvolver o seu projeto de escola, a criação do Conselho Nacional de Programas e a criação do Conselho de Ensino Superior. Já no campo da formação profissional, define-se que o Certificado de Aptidão Profissional - $C A P^{2}$ e o Brevet de Estudos Profissionais BEP sejam os diplomas mínimos e que no ensino superior, a prioridade seja dada aos métodos e aos conteúdos, bem como à cooperação internacional e à construção européia.

A luta pela igualdade de oportunidades passa a ser um princípio orientador da política educacional na qual se inscrevia a Lei Jospin, e, como consequência, contra o fracasso e exclusão escolar, por meio da busca da redução das desigualdadee geográficas, a ajuda às famílias e aos jovens.

A partir de 2002, com um número crescente de críticas oriundas do próprio Ministério da Educação francês, no segundo mandato do presidente Jacques Chirac (2002-2007), a idéia de reforma da Lei Jospin foi lançada.

É em 2004, então, que a Lei Fillon, nome do Ministro da Educação François Fillon, conhecida como Nouvelle loi d'orientation et de programme sur l'école (nova lei de orientação e de programa escolar), propõe reformulações que seriam válidas por um período de 15 anos. No ano seguinte, a Lei de Orientação e Programa para o Futuro da Escola n² 2005-380, de 23 de abril de 2005 é promulgada com o objetivo de assegurar a aquisição de um conjunto de conhecimentos e competências indispensáveis para todas as crianças ao final da escolaridade obrigatória, o chamado Socle Commun de Connaissances et de Compétences (Ciclo Comum de Conhecimentos e de Competências).

Desde então, com a publicação de um decreto complementar em 2006, o Ciclo Comum de Conhecimentos e Competências passou a se sustentar em 7 pilares:

1. O domínio da língua francesa;

2. A prática de uma língua estrangeira moderna;

3. Os principais elementos da Matemática e da cultura científica e tecnológica;

4. O domínio das técnicas usuais de informação e comunicação;

5. A cultura humanista;

6. As competências sociais e cívicas;

7. A autonomia e a iniciativa.

Assim, no interior desse ciclo, todas as disciplinas tiveram que ser organizadas para a aquisição das respectivas competências.

Foram criadas, também, avaliações nacionais para identificar competências adquiridas e as dificuldades de cada aluno. De acordo com o Ministério da Educação isto ajudaria a estabelecer um referencial nacional de formação e a instauração de um Contrato Individual de Sucesso Escolar (CIRE) para cada aluno com dificuldades, além do aumento da autonomia dos conselhos de classe para decisões ligadas à reprovação escolar.

\footnotetext{
${ }^{2}$ O CAP (Certificat d'aptitude Professionnelle) prepara para o exercício em cerca de 200 especialidades e é muito valorizado pelos empregadores. (www.education.gouv.fr)
} 
Em 2013, com a constatação da complexidade dos conteúdos escolares implementados no Ciclo Comum de Conhecimentos e de Competências e em razão de um contingente de alunos com dificuldades escolares, novas mudanças ocorreram na Educação Nacional.

O Ministério da Educação propõe então uma lei para refundar a escola (Lei $n^{\circ}$ 2013-595 de 8 de julho de 2013). Esta lei define quatro grandes objetivos: fazer com que todos os alunos dominem as competências em Francês e Matemática no final do CE1 (2 ano no Brasil), bem como os instrumentos essenciais do conhecimento no final do ensino fundamental; reduzir a menos de $10 \%$ a lacuna de domínio de conhecimentos no final do CM2 (5 ano no Brasil) entre os alunos da educação prioritária (em dificuldades) e não prioritária; reduzir a proporção de alunos que saem do sistema educativo sem qualificação, fazendo com que todos dominem o Ciclo Comum de Conhecimentos, de Competências e de Cultura, ao sair do ensino obrigatório; reafirmar os objetivos de conduzir $80 \%$ da faixa etária escolar ao baccalauréat e $50 \%$ a um diploma de ensino superior.

Com a prioridade dada ao ensino primário, ratificou-se o ensino de uma língua estrangeira moderna desde o curso preparatório ( $\mathrm{CP}$ - equivalente ao 1ㅇ ano no Brasil) e cinco eixos a serem seguidos pelo sistema educativo:

1. Assegurar uma verdadeira formação inicial e contínua dos professores, com a criação de Escolas Superiores do Professorado e de Educação (ESPE), que prepararão para o concurso de recrutamento de docentes e expedirão o título de Mestrado;

2. Fazer com que a escola entre na era digital;

3. Colocar o conteúdo de ensino e a progressão das aprendizagens no coração da refundação, criando conselhos escola-colégio que proponham conhecimentos e projetos pedagógicos comuns aos alunos do colégio e das escolas;

4. Renovar o sistema de orientação vocacional e inserção profissional;

5. Dinamizar o diálogo entre os parceiros da escola e instâncias de avaliação.

Em 9 de setembro de 2013 é publicada a Carta de Laicidade na Escola, contendo como princípios fundamentais da República a proibição de portar símbolos religiosos na escola, o caráter laico do ensino e dos programas escolares abertos a todas as áreas do questionamento científico, a obrigação dos funcionários de manter uma postura de neutralidade no ambiente escolar, a recusa às discriminações e a garantia de igualdade entre meninos e meninas.

Quanto à organização dos tempos escolares, após vários debates e estudos foi proposta uma readequação que equilibrasse o tempo de escola, de repouso, de férias, as atividades esportivas e culturais. Para isto, optou-se pelo abandono da semana de quatro dias de aula, respeitando-se a alternância entre sete semanas de aula e duas de férias escolares, e um encurtamento das férias de verão.

Tudo isso foi implementado na reforma dos ritmos escolares da escola primária, prevista no decreto no 2013-77 de 24 de janeiro de 2013, que visou repartir melhor o tempo de ensino ao longo da semana, a fim de facilitar as aprendizagens de todos os alunos, em particular dos mais frágeis. Desse modo, o decreto previu a implementação de uma semana escolar de 24 horas de ensino, repartidas em 9 meio turnos, à razão de, no máximo, cinco horas e trinta minutos por dia e, no máximo, três horas e trinta minutos por turno. Havendo autorização superior, poderiam ser ministradas aulas aos sábados de manhã, em substituição à quarta-feira de manhã, quando isto fosse justificado pelo projeto pedagógico escolar.

Após tais reestruturações, uma série de circulares e portarias foram publicadas para regulamentar os novos ritmos escolares na França. Sua implementação tem ocorrido ainda que com resistência e críticas dos sindicatos e pais de alunos. 
De forma breve, buscou-se evocar as principais revoluções e reformas sofridas pelo sistema educativo francês desde a $3^{\underline{a}}$ República. Na próxima parte será tratado sobre a estrutura e organização do sistema educativo francês.

\section{ESTRUTURA E ORGANIZAÇÃO DO SISTEMA EDUCATIVO FRANCÊS}

A organização do sistema educativo francês corresponde a uma administração central representada pelo Ministério da Educação Nacional, do Ensino Superior e da Pesquisa (MENESR) e uma administração descentralizada, composta pelas coletividades territoriais (regiões/departamentos/municípios).

A Constituição Federal de 1958 e o Código de Educação regem o sistema educativo francês em vigor.

De acordo com o Código de Educação, no ensino público professores e alunos devem respeitar os princípios da neutralidade política, assim como a laicidade em matéria religiosa. Isto implica o respeito às crenças de alunos e suas famílias, bem como uma ausência de instrução religiosa nos programas escolares.

Os princípios gerais da escola francesa são a gratuidade, a laicidade e a obrigação de escolarização. No que se refere a este último princípio, a obrigação é ligada à instrução, podendo ser dada nos estabelecimentos ou escolas públicas ou privadas ou nas próprias famílias através do esforço dos pais ou qualquer pessoa de sua escolha. Em outra palavras, a frequência à escola não é obrigatória, somente a organização de uma instrução que respeite as expectativas e os controles pelo Estado. $^{3}$

O serviço de ensino público coexiste com o privado, mas cabe ao Estado assegurar seu controle. Além disso, o Estado detém o monopólio da colação de graus acadêmicos, diplomas e certificados. O setor de ensino privado se divide em duas categorias: os estabelecimentos conveniados com o Estado que se beneficiam de recursos públicos, sendo submetidos às exigências nacionais e controles pelos serviços públicos; os estabelecimentos que não recebem nenhum subsídio do Estado, mas que gozam de uma autonomia forte.

Quanto à estrutura hierárquica, o sistema educativo francês está organizado em quatro níveis: o primeiro é o ministerial, que cuida das regulamentações em escala nacional; o segundo é o reitoral, que possui a missão de implementar as políticas educacionais elaboradas pelo ministério nas 30 academias ligadas a um rectorat (reitorado), cujo comando repousa sobre um reitor nomeado pelo ministro da educação; o terceiro se situa no nível da inspeção escolar; o quarto concerne aos chefes dos estabelecimentos e diretores de escola. (PIAU, 2008).

Conforme Vasconcellos e Bongrand (2013) há muito tempo percebido como arquétipo da centralização estatal, o sistema educativo francês é hoje principalmente administrado pelo Estado e pelas coletividades territoriais (regiões/ departamentos/ municípios).

Os serviços administrativos desconcentrados se compõem de trinta reitorados (administrações cujo recorte geográfico corresponde às academias) e, por quatro departamentos ou territórios de outros mares, vice-reitorados ou serviços da Educação Nacional. (VASCONCELLOS e BONGRAND, 2013)

Segundo o Ministério da Educação, a partir de 10 de janeiro de 2016, 17 regiões acadêmicas foram implementadas para responder à nova organização regional criada pela lei de 16 de janeiro de $2015^{4}$. No interior dessas 17 regiões acadêmicas, a França continua a ser repartida em 26 academias metropolitanas e 4 academias de outros mares. As mudanças efetuadas visam garantir uma proximidade para melhor gerir as escolas e a eficiência das reformas pedagógicas, de acordo com os territórios e expectativas dos usuários e parceiros locais. ${ }^{5}$

\footnotetext{
${ }^{3}$ Código de Educação - Parte Legislativa - Artigos L 111-1 a 111-2, 112-1, 121-1, 122-1, 131-1 a 131-5, 141-1.

${ }^{4}$ Lei $n^{\circ}$ 2015-29 de 16 de janeiro de 2015 relativa à delimitação das regiões, eleições regionais e departamentais. (www.legifrance.gouv.fr)

${ }^{5}$ www.education.gouv.fr
} 
Figura 1. Mapa das regiões acadêmicas e coordenadas dos reitorados - 2016.

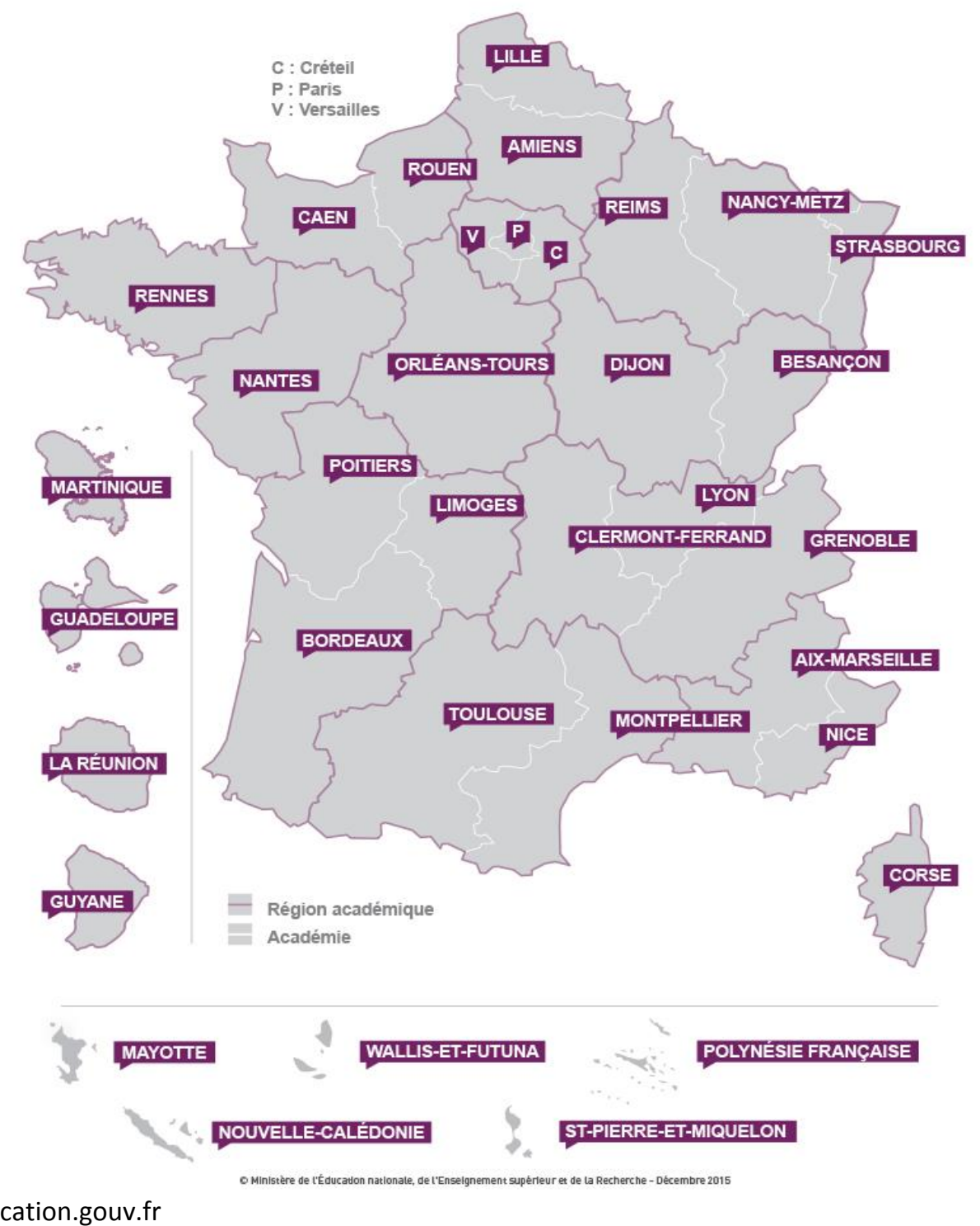

Fonte: www.education.gouv.fr

A região acadêmica constitui a escala de alinhamento das políticas educativas regionais, em particular quanto às questões que requerem uma coordenação com a região ou o prefeito da região nas seguintes áreas: formação e aprendizagem ao longo da vida profissional; definição do esquema de formação dos estabelecimentos públicos de ensino de segundo grau; ensino superior e pesquisa; luta contra o fracasso escolar; serviço público digital educativo; utilização do fundo de recursos europeu etc.

Em cada região acadêmica um reitor é nomeado para fazer a interlocução com o conselho regional e o prefeito da região. Já em cada academia, é nomeado pelo Presidente da República um reitor responsável pela totalidade dos serviços públicos de educação, da école maternelle (préescola) às universidades que pertencem à academia e aos departamentos que a constituem.

Em estreito contato com as universidades da academia e do reitorado as ESPEs (Escolas Superiores do Professorado e da Educação) têm a missão de assumir a preparação dos concursos de recrutamento de docentes e acompanhar o primeiro ano de docência dos professores estagiários nas escolas, colégios e liceus (estágio probatório). As ESPEs também expedem títulos de mestrado em educação e contribuem de forma privilegiada com as academias na formação contínua dos docentes, como forma de reforçar os laços entre os docentes pesquisadores e os docentes da escola básica. 
Em cada departamento que compõe a academia um diretor acadêmico de serviços departamentais da educação nacional (DASEN) atua de forma a decidir questões ligadas à estrutura pedagógica, a distribuição dos postos de trabalho das escolas e colégios, a formação contínua dos profissionais do primeiro grau e a validação dos projetos concernentes aos ritmos escolares semanais das escolas.

Ainda, no interior de cada departamento, as escolas de primeiro grau (école maternelle et élémentaire - pré-escola e ensino fundamental) são agrupadas dentro de uma circunscrição. Em média, cada uma delas é constituída de 30 a 50 escolas, que são dirigidas por um Inspetor da Educação Nacional (IEN). O IEN é o superior hierárquico direto dos docentes das escolas de educação infantil e ensino fundamental, cabendo a ele aconselhar, inspecionar, avaliar os docentes, emitir pareceres sobre o projeto escolar adotado pelo conselho de escola e os procedimentos para encaminhamento dos alunos para o colégio. Assistido por um ou vários conselheiros pedagógicos e mestres formadores que pertencem a sua circunscrição, ele organiza a formação contínua dos docentes sob sua responsabilidade.

No fim da escala hierárquica do sistema educativo francês encontram-se as escolas e os estabelecimentos escolares (colégios, liceus, escolas de primeiro grau e estabelecimentos regionais de ensino adaptado). Elas são dirigidas por diretores de escola (educação infantil e ensino fundamental) ou chefes de estabelecimento (colégios, liceus etc.).

\section{A REPARTIÇÃO DE COMPETÊNCIAS EM MATÉRIA DE EDUCAÇÃO}

Como já foi citado anteriormente, o sistema educativo francês é administrado pelo Estado e pelas coletividades territoriais (regiões/departamentos/municípios).

Segundo Rey (2013) em virtude do processo de descentralização - cujos dois principais atos são de 2 de março de 1982 e de 13 de agosto de 2004 - as coletividades territoriais tendem a acumular competências de administração do sistema educativo. Os conselhos municipais, departamentais e regionais intervêm nos níveis respectivos das escolas, colégios e liceus. Eles são principalmente encarregados de construir, equipar e manter as instalações escolares, organizar o transporte e a alimentação dos alunos, e, em particular, de recrutar e gerir os profissionais não docentes.

O Código de Educação detalha em sete $\operatorname{artigos~}^{6}$ algumas disposições importantes sobre as competências compartilhadas entre Estado e as coletividades territoriais. Vasconcellos e Bongrand (2013) e Auduc (2015) elaboraram uma tabela recapitulativa a respeito dos artigos supracitados e outros do Código de Educação. Para apresentá-la, fizemos algumas adaptações.

\footnotetext{
${ }^{6}$ Artigos L.211-1; L.211-8; L.212-4; L.212-15; L.213-2 e L.214-6 (www.legifrance.gouv.fr)
} 
Tabela 1. Repartição de competências em matéria de educação entre o Estado e as coletividades territoriais.

\begin{tabular}{|c|c|c|c|c|}
\hline Nível de responsabilidade & Escola & Colégio & Liceu & Universidade \\
\hline $\begin{array}{l}\text { Ensino: definição dos } \\
\text { programas }\end{array}$ & Estado & Estado & Estado & Estado \\
\hline $\begin{array}{l}\text { Diplomas: definição e } \\
\text { expedição }\end{array}$ & --- & Estado & Estado & Estado \\
\hline \multirow{2}{*}{$\begin{array}{l}\text { Construções, reformas, } \\
\text { ampliações, manutenção) }\end{array}$} & \multirow{2}{*}{$\begin{array}{l}\text { Municípios } \\
\text { Conselho } \\
\text { municipal }\end{array}$} & \multirow{2}{*}{$\begin{array}{l}\text { Departemento } \\
\text { Conselho geral }\end{array}$} & \multirow{2}{*}{$\begin{array}{c}\text { Região } \\
\text { Conselho regional }\end{array}$} & Estado \\
\hline & & & & $\begin{array}{c}\text { Contrato } \\
\text { Estado-Região }\end{array}$ \\
\hline \multirow{2}{*}{$\begin{array}{c}\text { Recursos para } \\
\text { equipamentos, } \\
\text { funcionamento e } \\
\text { manutenção/material } \\
\text { pedagógico }\end{array}$} & \multirow[b]{2}{*}{$\begin{array}{l}\text { Municípios } \\
\text { Conselho } \\
\text { municipal }\end{array}$} & $\begin{array}{l}\text { Departemento } \\
\text { Conselho geral }\end{array}$ & $\begin{array}{c}\text { Região } \\
\text { Conselho regional } \\
\end{array}$ & \multirow[b]{2}{*}{ Estado } \\
\hline & & $\begin{array}{c}\text { Uma parte das } \\
\text { despesas } \\
\text { pedagógicas é paga } \\
\text { pelo Estado }\end{array}$ & $\begin{array}{c}\text { Uma parte das } \\
\text { despesas } \\
\text { pedagógicas é paga } \\
\text { pelo Estado }\end{array}$ & \\
\hline $\begin{array}{l}\text { Gestão dos profissionais } \\
\text { docentes (recrutamento, } \\
\text { formação, remuneração } \\
\text { etc.) }\end{array}$ & Estado & Estado & Estado & Estado \\
\hline $\begin{array}{l}\text { Gestão dos profissionais } \\
\text { de saúde (médico, } \\
\text { psicólogo e assistente }\end{array}$ & Estado & Estado & Estado & Estado \\
\hline $\begin{array}{l}\text { Gestão dos profissionais } \\
\text { não docentes } \\
\text { (recrutamento, formação, } \\
\text { remuneração etc.) }\end{array}$ & $\begin{array}{c}\text { Municípios } \\
\text { Conselho } \\
\text { municipal } \\
\text { Agentes territoriais } \\
\text { especializados das } \\
\text { écoles maternelles } \\
\text { (ATSEM) }\end{array}$ & $\begin{array}{l}\text { Departa6mento } \\
\text { Conselho geral } \\
\text { Profissionais de } \\
\text { apoio, manutenção, } \\
\text { técnicos e da área } \\
\text { de alimentação }\end{array}$ & $\begin{array}{c}\text { Região } \\
\text { Conselho regional } \\
\text { Profissionais de } \\
\text { apoio, manutenção, } \\
\text { técnicos e da área } \\
\text { de alimentação }\end{array}$ & Estado \\
\hline \multirow[t]{2}{*}{ Competências particulares } & \multicolumn{3}{|c|}{$\begin{array}{l}\text { Sob a responsabilidade e após autorização do conselho de } \\
\text { administração ou de escola, o prefeito pode usar os locais e } \\
\text { equipamentos escolares do município para atividades culturais, } \\
\text { esportivas e sociais durante as horas em que eles não estiverem } \\
\text { sendo utilizados para aulas ou momentos de formação inicial e } \\
\text { contínua. }\end{array}$} & --- \\
\hline & $\begin{array}{c}\text { Municípios podem } \\
\text { modificar as horas } \\
\text { de entrada e saída } \\
\text { dos alunos }\end{array}$ & --- & $\begin{array}{l}\text { Financiamento dos } \\
\text { custos dos manuais } \\
\text { escolares }\end{array}$ & --- \\
\hline
\end{tabular}

Fonte: Adaptado de Vasconcellos e Bongrand (2013) ; Auduc (2015).

É possível constatar a partir dos dados expostos na tabela anterior a importância das coletividades territoriais no compartilhamento das competências educativas com o Estado. Além disso, fica evidente a relevância dos conselhos municipais ${ }^{7}$, gerais e regionais no cumprimento das

\footnotetext{
${ }^{7}$ Nos municípios de porte médio e importantes há também um prefeito adjunto e um diretor administrativo encarregados da educação.
} 
obrigações apresentadas (AUDUC, 2015). Assim, a cada ano, o orçamento do município, do departamento e da região permite a dotação, respectivamente, do orçamento das escolas, dos colégios e dos liceus. Para sua definição, o papel dos conselhos e, em particular, do Conselho Departamental da Educação Nacional (CAEN) é essencial para a análise da rede de escolas, transportes, construção dos colégios, subvenções etc.

\section{ORGANIZAÇÃO DOS NÍVEIS DE ENSINO}

Em relação aos níveis de ensino, o sistema educativo francês está organizado em três etapas: a) ensino primário, composto pelo ensino pré-elementar e ensino elementar; b) ensino secundário, composto pelo colégio e pelo liceu; c) ensino superior.

A fim de possibilitar uma melhor compreensão da organização escolar na França, nos itens a seguir será indicada a nomenclatura oficial e a etapa ou termo equivalente no Brasil, para os respectivos níveis de ensino.

\section{ENSINO PRIMÁRIO}

A escolaridade primária abrange os primeiros anos da escola, distribuídos entre a école maternelle/escola maternal (pré-escola) e a école élémentaire/escola elementar (anos iniciais do ensino fundamental). Ela se dirige principalmente às crianças de 3 a 11 anos e se divide em três ciclos: Ciclo 1 - das primeiras aprendizagens, que engloba a escola maternal; Ciclo 2 - das aprendizagens fundamentais, que engloba os três primeiros anos da escola elementar e Ciclo 3 das consolidações, que corresponde aos dois últimos anos da escola elementar.

No início do ano letivo de 2014, o número de alunos do ensino primário era de 6.788. 600, dos quais $5.880 .900(86,6 \%)$ estavam matriculados em escolas do setor público. A média de alunos por classe era de $\mathbf{2 5 , \mathbf { 8 }}$ na escola maternal e de $\mathbf{2 3 , 0}$ na escola elementar. (MENESR, 2015)

\section{ENSINO PRÉ-ELEMENTAR / ESCOLA MATERNAL}

Instituída pelo decreto de 2 de agosto de 1881, a escola maternal que constitui a etapa prévia da escolarização obrigatória, foi integrada à escola primária desde a 3 a República. $^{8}$ (SZYMANKIEWICZ, 2013).

Sua organização consiste da pequena, média e grande seção, em função da idade das crianças $^{9}$. As dependências das escolas maternais pertencem aos municípios que são responsáveis por sua manutenção. Em 2014, a França contava com 15.079 escolas maternais públicas e 137 privadas. (MENESR, 2015).

Tabela 2. Estrutura da escola maternal na França

\begin{tabular}{|c|c|c|}
\hline \multicolumn{3}{|c|}{ Escola maternal } \\
\hline \multicolumn{3}{|c|}{ Ciclo 1 das « primeiras aprendizagens » } \\
\hline Pequena Seção (PS) & Média Seção (MS) & Grande Seção (GS) \\
\hline $2-3$ anos & $4-5$ anos & $5-6$ anos \\
\hline
\end{tabular}

Fonte: www.education.gouv.fr

Segundo o Ministério da Educação, a escola maternal é uma etapa essencial do percurso dos alunos para garantir seu sucesso escolar, sendo sua principal missão construir o desejo nas crianças de ir à escola para aprender, afirmar e desenvolver sua personalidade.

\footnotetext{
${ }^{8}$ Período de 1870 a 1940.

${ }^{9}$ As crianças de menos de 3 anos podem ser escolarizadas em modalidades de acolhimento diferentes: em uma classe da escola maternal, específica e adaptada às necessidades das crianças pequenas (Pequenina seção - TPS) ; em uma classe mista da escola maternal ou em uma creche local). Na França, em 2014, 11,8\% das crianças de 2 a 3 anos foram escolarizadas na escola maternal. (www.education.gouv.fr) 
Os principais objetivos da escola maternal estão ligados ao " aprender juntos e viver juntos ", desenvolvendo sua linguagem e começando a descobrir a escrita, os números e os outros domínios da aprendizagem. O ensino nesta etapa é organizado em cinco domínios de aprendizagem:

- Mobilizar a linguagem em todas as suas dimensões.

- Agir, se expressar, compreender através da atividade física.

- Agir, se expressar, compreender através das atividades artísticas.

- Construir as primeiras ferramentas para elaborar seu pensamento.

- Explorar o mundo.

O ano escolar na escola maternal, assim como na escola elementar, começa geralmente em 1 ㅇ de setembro e acaba no começo do mês de julho do ano seguinte. Sua duração é de 36 semanas letivas, respeitando-se a alternância de sete semanas de aulas e duas de férias, além das férias de verão em julho/agosto. A jornada semanal é de 24 horas de ensino após a reforma dos ritmos escolares, ou seja, 864 horas anuais.

\section{ENSINO ELEMENTAR}

A escola elementar acolhe as crianças de 6 a 11 anos e é gratuita se pertencente ao setor público. Comporta cinco níveis de ensino: CP, CE1, CE2, CM1 e CM2 e suas dependências físicas pertencem ao município, que se ocupa da sua manutenção. Em 2014, a França contava com 31.883 escolas elementares públicas e 5.126 privadas. (MENESR, 2015)

Tabela 3. Estrutura da escola elementar na França.

\begin{tabular}{|c|c|c|}
\hline Idade & Séries do Ensino Elementar & Estrutura \\
\hline 6-7 anos & Classe Preparatória (CP) & \multirow{3}{*}{$\begin{array}{l}\text { Ciclo } 2 \text { - das } \\
\text { aprendizagens } \\
\text { fundamentais }\end{array}$} \\
\hline $7-8$ anos & Curso elementar 10 ano (CE1) & \\
\hline $8-9$ anos & Curso elementar $2^{\circ}$ ano (CE2) & \\
\hline 9-10 anos & Curso médio 10 ano (CM1) & \multirow{2}{*}{$\begin{array}{l}\text { Ciclo } 3 \text { - das } \\
\text { consolidações }\end{array}$} \\
\hline $10-11$ & Curso médio 20 ano (CM2) & \\
\hline
\end{tabular}

Fonte: www.education.gouv.br.

Os programas de ensino elementar são nacionais e obrigatórios para todos os professores e alunos, uma vez que integram o "Ciclo Comum de Conhecimentos, de Competências e de Cultura ", que começa na escola primária e termina no liceu (ensino médio). As competências esperadas dos alunos são fixadas por ciclo.

Para o Ciclo 2 das « aprendizagens fundamentais » (CP, CE1 e CE2) os objetivos prioritários são a aprendizagem da leitura, da escrita e da língua francesa; o conhecimento e a compreensão dos números e quantidades, sua escrita em cifras (numeração decimal) e o cálculo de pequenas quantidades. 
Tabela 4. Horários e programas do CP, CE1 e CE2.

\begin{tabular}{|l|c|c|}
\hline \multicolumn{2}{|c|}{ Ciclo 2 das « aprendizagens fundamentais » CP, CE1 e CE2 } \\
\hline \multicolumn{1}{|c|}{ Campos disciplinares } & Duração anual & Duração semanal \\
\hline Francês & 360 horas & 10 horas \\
\hline Matemática & 180 horas & 5 horas \\
\hline Educaçao Física e Esportiva & 108 horas & \multirow{2}{*}{9} \\
\cline { 1 - 2 } Língua estrangeira moderna* & 54 horas \\
\hline Práticas artísticas** & 81 horas & \\
\hline Descoberta do mundo & 81 horas & 24 horas \\
\hline \multicolumn{1}{|c|}{ TOTAL } & 864 horas & \multirow{2}{*}{} \\
\hline
\end{tabular}

* Língua estrangeira ou regional / ** Artes visuais e educação musical.

Fonte: Auduc (2015)

No Ciclo 2 os alunos do CP, CE1 e CE2 também seguem um ensino sobre os primeiros elementos de uma educação cívica, baseada na aprendizagem de regras de polidez e de comportamento em sociedade.

Novas aprendizagens são propostas no Ciclo 3 das consolidações (CM1 e CM2): literatura; história e geografia; ciências experimentais e tecnologia.

Tabela 5. Horários e programas do CM1 e CM2.

\begin{tabular}{|l|c|c|}
\hline \multicolumn{2}{|c|}{ Ciclo 3 das « consolidações » CM1 e CM2 } \\
\hline \multicolumn{1}{|c|}{ Campos disciplinares } & Duração anual & Duração semanal \\
\hline Francês & 288 horas & 8 horas \\
\hline Matemática & 180 horas & 5 horas \\
\hline Educaçao Física e Esportiva & 108 horas \\
\hline $\begin{array}{l}\text { Língua estrangeira moderna* } \\
\text { Ciências experimentais e } \\
\text { ternologia }\end{array}$ & 74 horas \\
\hline $\begin{array}{l}\text { Cultura humanista: } \\
\text { - Práticas artísticas e história } \\
\text { das artes** } \\
\text { - História-Geografia } \\
\text { Educação cívica }\end{array}$ & 78 horas & \multirow{2}{*}{11 horas } \\
\hline TOTAL & 78 horas & \\
\hline
\end{tabular}

* Língua estrangeira ou regional.

** O ensino da história das artes é de 20 horas.

Fonte: Auduc (2015)

Um aspecto importante a se ressaltar é o fato de que o trabalho com as tecnologias da informação e comunicação é uma ferramenta empregada nas diversas atividades escolares, cuja apropriação conduzirá ao primeiro nível do Brevet informatique et internet (B2i) ${ }^{10}$.

\footnotetext{
${ }^{10} \mathrm{O}$ brevet informatique et internet (B2i) é um certificado que atesta o nível de domínio das ferramentas multimídias e de internet dos alunos. 


\section{ENSINO SECUNDÁRIO}

O segundo nível de escolaridade na França é o ensino secundário, que se organiza em dois ciclos principais: Ciclo 1 (colégio) e Ciclo 2 (liceu). O colégio se destina principalmente aos alunos de 11 a 14 anos e se subdivide em três ciclos: " adaptação; central; orientação ". O liceu se destina principalmente aos alunos de 15 a 17 anos e se subdivide em dois ciclos: "determinação; terminal $»$.

No início do ano letivo de 2014, o número de alunos do ensino secundário era de 5.497.100, dos quais $4.335 .000(78,9 \%)$ estavam matriculados em escolas do setor público. A média de alunos por classe era de $\mathbf{2 5 , 1}$ no primeiro ciclo (colégio), $\mathbf{1 8 , 9}$ no segundo ciclo profissional (liceu profissional-LP) e de $\mathbf{2 9 , 0}$ no segundo ciclo geral e tecnológico (liceu de ensino geral e tecnológico). (MENESR, 2015)

\section{COLÉGIO}

O colégio é o estabelecimento de nível secundário que, na saída da escola elementar, acolhe todos os alunos escolarizados para o prosseguimento de quatro anos de estudo nas

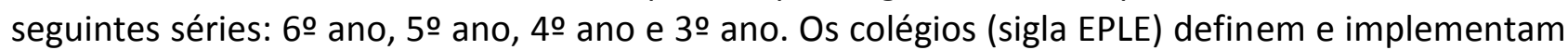
um projeto de estabelecimento que lhes permite tomar iniciativas e ser autônomos.

A gestão das instalações dos colégios provém dos departamentos, em conformidade com as leis de descentralização. Em 2014, a França possuía 5.279 colégios públicos e 1.796 privados. (MENESR, 2015).

Tabela 6. Estrutura do Colégio na França.

\begin{tabular}{|c|c|c|}
\hline Idade & Séries do Colégio & Estrutura \\
\hline $11-12$ & Sixième (6o ano) & Ciclo de adaptação \\
\hline $12-13$ & Cinquième (5 ano) & \multirow{2}{*}{ Ciclo central } \\
\hline $13-14$ & Quatrième (4 ano) & Ciclo de orientação \\
\hline $14-15$ & Troisième (3 ano) \\
\hline
\end{tabular}

Fonte: www.education.gouv.br.

O ensino no colégio é estruturado em disciplinas: francês, matemática, história-geografia, educação cívica, língua estrangeira moderna, ciências da vida e da Terra, tecnologia, artes plásticas, educação musical, educação física e esportiva e físico-química. A história das artes e a informática são ensinadas no decurso normal das aulas durante toda a escolaridade no colégio. A jornada semanal para todos os alunos inclui 26 horas, às quais podem ser adicionadas atividades complementares ${ }^{11}$.

Em relação a sua estruturação, o colégio se organiza em três ciclos. No Ciclo de Adaptação (60 ano) o objetivo é consolidar as aprendizagens da escola elementar e iniciar os alunos nos métodos de trabalho do colégio. Para isto, eles recebem um acompanhamento personalizado.

No Ciclo Central (5ㅇ e 4ㅇ anos), o objetivo é permitir aos alunos aprofundar seus "saberes e saber-fazer", pois nele ao longo dos dois anos os alunos experimentam de forma coerente a progressão dos conteúdos e o enriquecimento gradativo por meio de disciplinas e atividades de opção facultativa. Desse modo, os estabelecimentos dispõem de 2 horas semanais para a organização de itinerários de descoberta. ${ }^{12}$

O Ciclo de Orientação (3ำ ano) permite completar as aquisições do colégio e preparar para as formações geral, tecnológica e profissional. Nessa etapa, os alunos prosseguem a aprendizagem de línguas estrangeiras modernas estudadas na classe de 4o ano ou podem escolher, a título

\footnotetext{
${ }^{11}$ Os campos disciplinares e respectivas cargas horárias semanais não serão detalhados em razão de sua complexidade e necessidade de uma análise exaustiva.

${ }^{12}$ Os itinerários de descoberta permitem aos alunos escolher duas disciplinas para uma formação complementar de 2 horas na semana. 
facultativo, uma língua antiga (latim ou grego); uma opção de descoberta profissional de três horas semanais ou um período de preparação para a via profissional.

Ao final do 30 ano, os alunos obtêm o diploma nacional do brevet (ensino secundário) e podem se orientar em direção à: 1) uma classe de 20 ano do liceu geral e tecnológico; 2) uma classe de 20 ano profissional ou um 10 ano de preparação ao certificado de aptidão profissional (CAP) em um liceu profissional.

\section{LICEU}

Ao final do colégio, os alunos podem prosseguir seus estudos em um liceu de ensino geral e tecnológico ou em um liceu profissional, perpassando três anos de escolaridade: 20 ano, 30 ano e terminal. Cada liceu elabora um projeto educativo que lhe permite possuir uma política particular em função de seu público escolar.

Em relação a sua construção e manutenção, os liceus públicos, conforme as leis de descentralização, são administrados pela região.

Em 2014, a França contava com 1.595 liceus gerais e tecnológicos públicos, 901 liceus profissionais públicos, 1.040 liceus gerais e tecnológicos privados e 502 liceus profissionais privados (MENESR, 2015). Esses dados mostram a força do setor de ensino privado nesse nível de escolarização.

Tabela 7. Estrutura do liceu na França.

\begin{tabular}{|c|c|c|}
\hline Idade & Séries do Liceu & Estrutura \\
\hline $15-16$ & Seconde ( 2 o ano $)$ & Ciclo de \\
\hline $16-17$ & Première (1 ano) & \multirow{2}{*}{ Ciclo terminal } \\
\hline $17-18$ & Terminale (Terminal) \\
\hline
\end{tabular}

Fonte: www.education.gouv.br.

O liceu de ensino geral e tecnológico (LEGT) compreende três classes: classe de 20 ano geral e tecnológico, comum aos alunos que se destinam a prosseguir os estudos em uma das vias geral ou tecnológica. A escolha entre essas duas vias se efetua ao término dessa classe. As classes de 10 ano e terminal nas diferentes séries conduzem ao exame do baccalauréat, que sanciona os conhecimentos e competências de fim dos estudos secundários e constitui o primeiro grau do ensino superior, permitindo o prosseguimento dos estudos superiores.

A via geral compreende três séries que conduzem ao baccalauréat geral. Ela permite o prosseguimento dos estudos superiores principalmente na universidade, classe preparatória das grandes escolas ou em uma escola especializada.

Figura 2. Formações possíveis nos liceus franceses

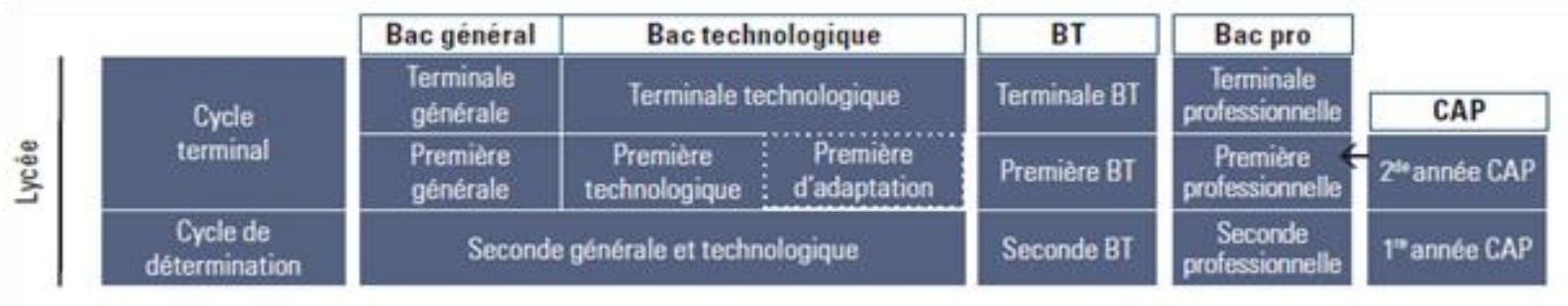

Fonte: Autor.

A via tecnológica prepara para os estudos superiores tecnológicos (em dois anos) e permite continuar uma formação mais rigorosa que conduza a uma licença profissional ou ao diploma de engenheiro. O baccalauréat tecnológico comporta as seguintes opções: STL: "ciências e tecnologia 
de laboratório"; STI2D: "ciências e tecnologias da indústria e do desenvolvimento durável"; STD2A: "ciências e tecnologia do design e das artes aplicadas"; STMG: "ciências e tecnologias da gestão"; ST2S: "ciências e tecnologias da saúde e do social"; TMD: "técnicas da música e da dança"; Hotelaria e STAV: "ciências e tecnologias da agronomia e da vida".

No liceu profissional (LP), os ensinos tecnológico e profissional representam de 40 a $60 \%$ do emprego do tempo de um aluno, sendo ministrados sob a forma de aulas em classe e, de acordo com as especialidades, em oficinas, laboratórios ou em campo. As matérias de ensino geral (francês, matemática, história e geografia, ciências, inglês) ocupam também um lugar importante.

Após o 3으 ano (colégio), os alunos que entram no liceu profissional podem se preparar para o baccalauréat profissional (Bac pro) ou um certificado de aptidão profissional (CAP) ${ }^{13}$. A obtenção de um brevet de estudos profissionais (BEP) também é possível, pois sua preparação é integrada ao percurso em três anos de baccalauréat profissional. $O$ baccalauréat profissional é realizado em três anos após o 3ํ ano colegial e permite o exercício de uma atividade profissional altamente qualificada em uma das mais de 75 especialidades. Caso o aluno mantenha como objetivo prioritário sua inserção profissional, o prosseguimento de estudos em BTS ${ }^{14}$ também pode ocorrer.

Em síntese, há várias possibilidades de escolha de formação nos liceus franceses, e para o sucesso dos alunos, o sistema educativo coloca à disposição acompanhamentos personalizados, tutorias, estágios de nivelamento e estágios supervisionados.

Tabela 8. Proporção de bacharéis (1851-2014).

\begin{tabular}{|c|c|c|c|}
\hline Bac profissional & Bac tecnológico & Bac geral & Total \\
\hline $24,1 \%$ & $16,2 \%$ & $38,0 \%$ & $78,3 \%$ \\
\hline
\end{tabular}

Fonte: MENESR (2015)

\section{ENSINO SUPERIOR}

Último nível do sistema educativo francês, o ensino superior ${ }^{15}$ está organizado sob a forma de Licença (3 anos), Mestrado (2 anos) e Doutorado (3anos), dito sistema LMD, mas existem, ainda, outras vias como as Grandes Escolas, cujas formações possuem uma duração de 5 anos e equivalem a um mestrado, as classes superiores dos liceus - o BTS (Brevet de Técnico Superior) e os IUT (Institutos Universitários de Tecnologia) que preparam para o DUT (Diploma Universitário de Tecnologia), com duração de 2 anos de estudos ${ }^{16}$.

\footnotetext{
${ }^{13}$ O CAP é preparado em dois anos após o 30 ano colegial. Ele dá acesso a uma profissão específica, enquanto trabalhador ou empregador qualificado, tendo por objetivo principal a entrada direta na vida profissional. Existem cerca de 200 especialidades de CAP. www.education.gouv.fr/

${ }^{14}$ O Brevet de Técnico Superior « BTS " é um diploma curto que se prepara em dois anos após o BAC (formação de nível III / Bac +2). Um fator de sucesso para esse diploma é que ele permite optar por uma formação de BTS em alternância (1 semana na empresa / 1 semana em formação) http://etudiant.aujourdhui.fr/

${ }^{15} \mathrm{Na}$ França a maioria das universidades é pública, sendo as privadas raras e pertencentes a ordens religiosas.

${ }^{16} \mathrm{http}: / /$ www.enseignementsup-recherche.gouv.fr/ 
Figura 3. Principais fileiras de formação superior - 2016.

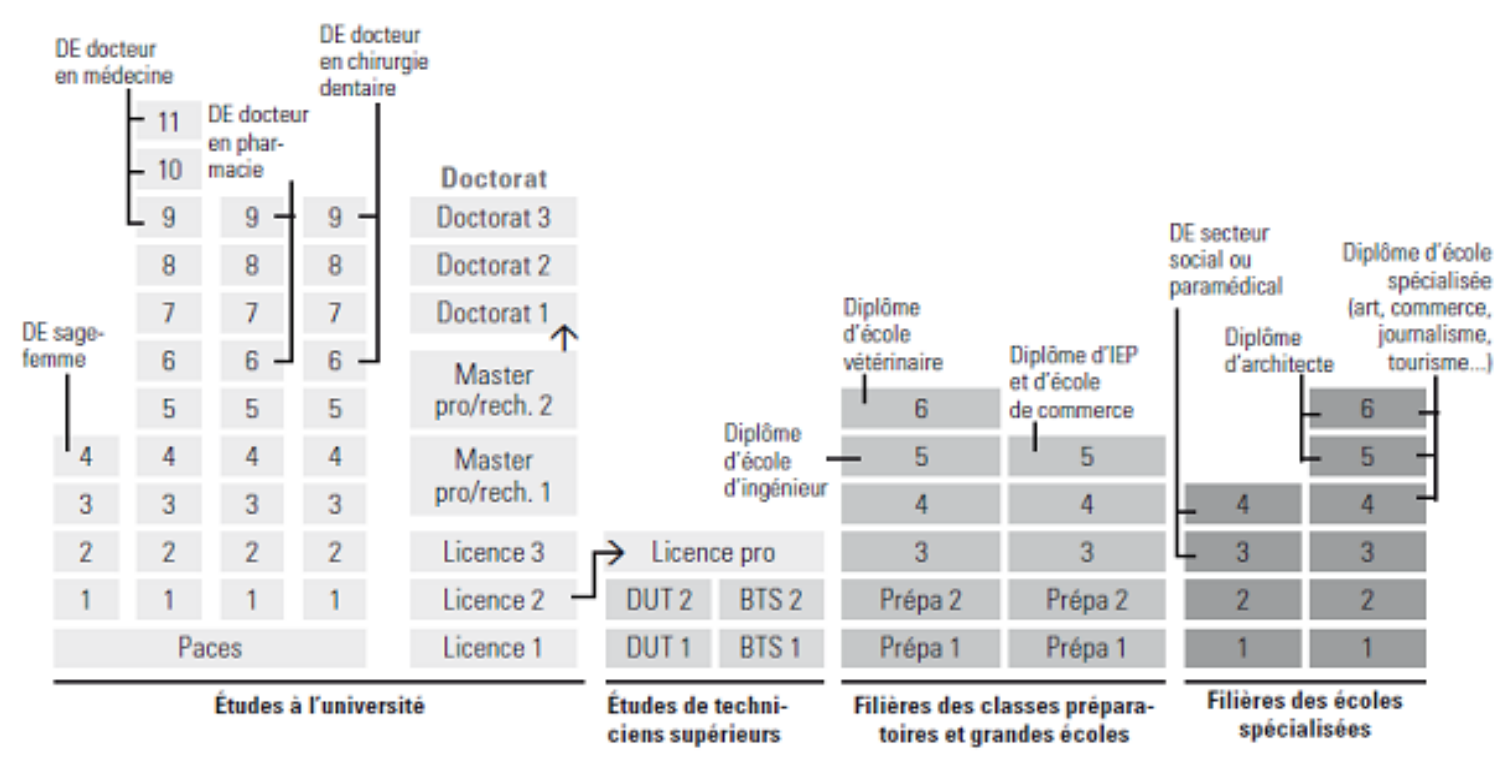

Fonte: MENESR (2015)

Em relação à formação inicial dos docentes, tal como já foi brevemente citado neste estudo, ela se desenvolve em três anos de licença em qualquer área e, a seguir, nas Escolas Superiores do Professorado e da Educação (ESPE), que integram as universidades.

As ESPEs acolhem o conjunto de futuros docentes, estejam eles interessados em atuar na escola maternal e elementar, no colégio, no liceu ou na universidade. Para isto, organizam mestrados profissionais em educação - MEEF (métiers de l'enseignement, de l'éducation et de la formation), com duração de 2 anos. Após a realização dos mestrados em educação nas ESPEs, os docentes podem prestar os concursos públicos de acesso à carreira docente.

Figura 4. A formação inicial docente na ESPE.

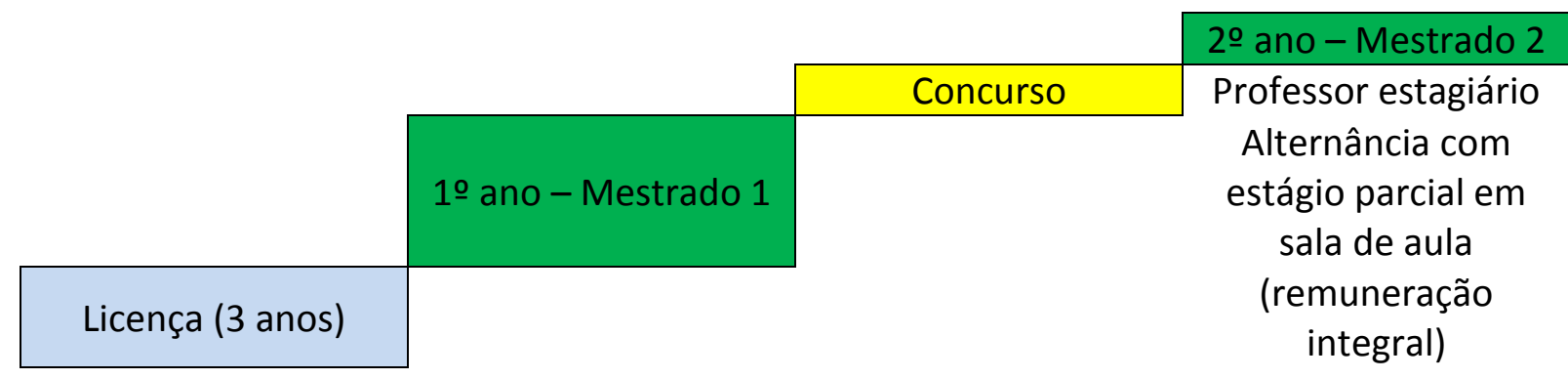

UNIVERSIDADE

ESPE

Fonte: Autor.

Espera-se ter sido possível apresentar, ainda que sucintamente, os principais aspectos históricos e organizacionais que constituem o sistema educativo francês, cabendo por derradeiro lembrar, o quão complexo seria explorá-lo mais detidamente, dadas as limitações deste estudo.

\section{CONSIDERAÇÕES FINAIS}

Este artigo teve por objetivo apresentar uma análise sintética do sistema educativo francês a partir de seu percurso histórico, estrutura hierárquica e de seus níveis de ensino, desde a escola maternal até a universidade. 
Evidenciou-se que a educação na França passou a expandir-se a partir das Leis Guizot (1833), Jules Ferry (1881-1882) e reforma Haby de 1976, que estimularam a instalação de escolas primárias nos municípios e fixaram a obrigatoriedade escolar dos 6 aos 16 anos. Outras questões importantes discutidas foram os impactos da lei de orientação de 1989 e do programa para o futuro da escola lançado em 2005, que culminaram com a definição de um Ciclo Comum de Conhecimentos e Competências a serem atingidas por todos os alunos ao final da escolaridade obrigatória.

Além disso, enfatizou-se os novos ritmos escolares implementados em 2013, a organização do sistema educativo francês quanto à responsabilidade compartilhada entre as coletividades territoriais (Estado, região, departamento e município) e a estruturação dos diferentes níveis de ensino (escola maternal, escola elementar, colégio, liceu e ensino superior), perpassando rapidamente o sistema de formação inicial dos docentes nas universidades públicas.

Com todas as questões que se procurou abordar ao longo deste texto pretendeu-se tornar visível que mesmo um país milenar e desenvolvido como a França possui seus percalços e dificuldades na implementação de suas políticas educacionais. É dentro dessa perspectiva que se acredita que o conhecimento do sistema educativo francês serve de ponto e contraponto para uma séria reflexão quanto à compreensão dos diferentes caminhos que cada contexto pode adotar para a construção da singularidade de um povo.

\section{REFERÊNCIAS}

AUDUC, L. J. Le Système Éducatif Aujourd'hui: de la maternelle à la terminale. Hachette Éducation; Paris, 2015.

DEUBEL (dir.), P., HUART, J. M., MONTOUSSÉ, M., VIN-DATICHE, D. 100 fiches pour comprendre le système éducatif. $4{ }^{\mathrm{e}}$ édition, Breal, Levallois-Perret, 2011.

Ministère de l'Éducation nationale, de l'Enseignement supérieur et de la Recherche (MENESR). L'Éducation nationale en chiffres. Paris, 2015.

PAZ, F. M. da. Gestion Scolaire, Formation des Enseignants et Qualité de l'Éducation: les contextes éducatifs à Lyon - France et à Birigui - Brésil. Éditions Universitaires Européennes, 2017.

PIAU. L. Le guide juridique des enseignants: écoles, collèges et lycées de l'enseignement public, ESF, Issy-les-Moulineaux, 2008.

REY. O. Décentralisation et politiques éducatives, Dossier d'actualité Veille et Analyses, $n$ ㅇ 83, http://ife.ens.lyon.fr/vst, 2008.

SZYMANKIEWICZ, C. Le système éducatif en France. $4^{\mathrm{e}}$ édition, La documentation Française, Paris, 2013.

VASCONCELLOS, M., BONGRAND, P. Le système éducatif. $5^{\mathrm{e}}$ edition, La Découverte, Paris, 2013. 